\title{
Work-type influences perceived livestock herding success in Australian Working Kelpies
}

Jonathan B. Early, Elizabeth A. Arnott, Lisa J. Mascord, Diane van Rooy, Paul D. McGreevy and Claire M. Wade* (D)

\begin{abstract}
Background: Working dog handlers and breeders have very different behavioural requirements in the animals that they employ for managing livestock. The Australian Working Kelpie breed may be used in several working contexts, notably yards, paddocks and a combination of both. The working context influences the skillsets required and gives rise to three corresponding work-types: Yard, Paddock and Utility Kelpies. In particular, dogs used for working stock in the confines of yards and trucks interact with stock more forcefully than those mustering in larger areas (paddocks) where they can herd stock effectively from a greater distance. This article explores owner assessments of dog working quality and assessment of genomic similarity by multidimensional scaling, to ask whether it is sufficient for breeders to aim for a multipurpose breeding objective, or whether breeding only specialist lines maximises user satisfaction for yard and paddock work.
\end{abstract}

Results: Reported owner perceptions of 298 dogs assessed with the Livestock Herding Dog assessment tool showed that dog handlers across all working types were very happy with their dogs' level of general skills.

Compared with both Yard and Utility Kelpies, Paddock Kelpies had significantly lower trait scores for force (pressure applied by the dog to move livestock), willingness to back the stock (run along a sheep's dorsum) and bite (frequency of using the mouth to grab or bite the livestock). Meanwhile, compared with both Paddock and Utility Kelpies, the Yard Kelpies had significantly higher scores for hyperactivity and excitability (both with and without stock) and impulsiveness without stock. As one would predict for all-rounders, Utility Kelpies had intermediate scores for all behaviours and working traits.

Conclusions: Specialist characteristics were displayed by dogs in the Yard Kelpie and Paddock Kelpie groups. In particular, Yard Kelpies demonstrate higher excitability, willingness to back the stock, and a higher tendency to bark and bite the stock. Conversely, Paddock Kelpies rarely display these characteristics. Utility Kelpies, as the name suggests, are intermediate between the other two groups and display the characteristics of both. Genetic analysis suggests that the Yard, Utility and Paddock Kelpies are not distinguishable at a DNA level. In conclusion, at this time there is no suggestion of a breed split in the Australian Working Kelpie generated by selection for work type. A common breeding objective should enable dogs to be produced that fulfil all potential working requirements. This reinforces the importance of breeder skill in recognising the phenotypic potential of pups in order to place them in appropriate working contexts.

Keywords: Kelpie, Behaviour, Livestock, Working-type

\footnotetext{
* Correspondence: claire.wade@sydney.edu.au

Faculty of Science, University of Sydney, Camperdown, NSW 2006, Australia
}

(c) The Author(s). 2018 Open Access This article is distributed under the terms of the Creative Commons Attribution 4.0 International License (http://creativecommons.org/licenses/by/4.0/), which permits unrestricted use, distribution, and reproduction in any medium, provided you give appropriate credit to the original author(s) and the source, provide a link to the Creative Commons license, and indicate if changes were made. The Creative Commons Public Domain Dedication waiver (http://creativecommons.org/publicdomain/zero/1.0/) applies to the data made available in this article, unless otherwise stated. 


\section{Plain English summary}

Dogs from the Australian Working Kelpie breed were categorised by their owners and handlers into different working type categories. Dogs from this breed may be used in several working contexts, notably moving stock in the close quarters of stock yards, through large fields and a combination of both. The working context influences the skills required by the dog and gives rise to three corresponding work-types: Yard, Paddock and Utility Kelpies. We compared the work-type and personality attributes of dogs that were declared by their owners to be one of the three working types. Yard Kelpies demonstrated higher excitability, willingness to back the stock, and a higher tendency to bark and bite the stock. Conversely, Paddock Kelpies rarely displayed these characteristics. Utility Kelpies, as the name suggests, were intermediate between the other two groups and displayed the characteristics of both. Genetic analysis suggests that the Yard, Utility and Paddock Kelpies are not distinguishable at a DNA level suggesting that there is no current genetic breed split that is related to the different working types.

\section{Background}

The Farm Dog Project at the University of Sydney aims to better understand the phenotypic behavioural attributes (traits and manoeuvres) that characterise excellent livestock herding dogs. It is well understood that there is a major breed split between Australian Working Kelpies (AWK) and conformation-bred Australian Kelpies (AK) [1]. However, people outside of the working dog community are largely unaware of a further perceived split among the AWK. While some AWK breeders specialise in producing dogs with specialised attributes suited to paddock (extensive) or yard (intensive) stock work, others aim to produce dogs that can "do it all".

\section{The Australian working kelpie}

The Australian Working Kelpie (AWK) was developed in the late nineteenth Century from three pairs of "Working Collies" imported into Australia from Scotland [2]. All of the early pairs were black and tan or solid black with little or no white markings [2]. Two bitches from the early intermingling of these pairs had the call-name "Kelpie". One of the first to be bred from was "Gleeson's Kelpie". This animal was bred with an all-black dog "Moss" and one female pup from the resultant litter "King's Kelpie" displayed outstanding working ability in herding trials, although the metrics supporting this assessment are unavailable. She went on to found the Kelpie breed. Breed registrations are maintained by the Working Kelpie Council of Australia and the registry is "open" allowing unregistered animals with good working ability to be crossed into the breed. Despite being tough and relatively free from inherited disorders, the so-called working failure resulting in cull of livestock herding dogs, chiefly Kelpies, in Australia has been estimated at around 20\% [3].

\section{Three dominant working types within the AWK}

Working types of Kelpie are detailed in other work [3-5], but briefly:

Paddock Kelpies are used to gather (muster) animals from extensive open fields and ranges. These dogs are required to show great intelligence (sagacity), work independently from the human handler, calmly and effectively gathering the stock without unduly disturbing them. They typically start work facing the front of the stock, running around the periphery of the mob in an extensive cast and then using their behavioural characteristics of eye and hold, pressure the animals into a single group that they can move calmly towards the handler, who typically remains at the mob's targeted destination (such as a gate).

Yard Kelpies work at close quarters to the livestock, pushing them through networks of yards for the purposes of transit (e.g. loading onto trucks), husbandry (e.g. for shearing or routine medication) or slaughter. This working type typically uses forceful measures to move the stock out of corners and through tight spaces (force, bark, bite) and they may move rapidly and efficiently around the yarding system by backing the animals (the action of a dog jumping up onto a sheep's backs to assist in moving those sheep that are at the head of the mob). Yard dogs work under the direction of the handler and may work either at the front or the rear of the stock.

Utility Kelpies are general purpose livestock herding dogs. These animals are expected to muster (the traits demonstrated by the Paddock dogs) but are also expected to do move animals around the stock-yards or onto trucks.

Among these types, the Paddock and Yard dogs are regarded as specialised while the Utility dog is a generalist type.

\section{Aims}

In the current study, we analyse owners' reports of the individual phenotypes of their dogs that were categorised by their owners into one of three working types (Paddock, Yard and Utility). Dogs that were categorised across multiple types are recorded as Utility dogs. We then explore the major working behaviour requirements of these types and ask whether it is possible in a single breeding program to breed dogs that have the required expression of every working characteristic to work across the spectrum and, if so, the extent to which users' expectations of the "working-quality" of the dogs has to be moderated for the working context. Understanding these requirements will refine relevant breeding objectives for the three major working types and provide resources to direct dog buyers to 
appropriate breeders. Better matching of clients and breeders is expected to result in better welfare outcomes and reduced wastage.

\section{Methods}

The Livestock Working (Herding) Dog Assessment Form was designed to elicit data from livestock working dog handlers on the perceived quality of performance of their dogs according to 63 working and behavioural metrics, described in detail elsewhere [6]. Of the responses recorded as of May 19 2017, 298 participants' dogs were described as being of the Kelpie breed. Among these, 35 were described as Yard dogs, 115 as Paddock dogs and 145 as Utility working dogs. Responses were recorded via a web based survey tool that enables participation from handlers Australia wide. Pedigree information on survey participants was not available.

For each trait (such as eye) and desirable manoeuvre (such as cast), the descriptive metrics from the assessment form were converted to numerical scores (Additional file 1: Table S1) and Glossary. For these scores, means and variances were estimated within each of the three dog working-types. Dog phenotype scores for each trait and manoeuvre were compared across work-types (Paddock versus Yard, Paddock versus Utility, Yard versus Utility) using a Welch's t-test [7] with Welch-Satterthwaite degrees of freedom. Probabilities were determined from critical values of the Student's t-distribution using the t.test function in Microsoft Excel. Significant Welch's t-test scores were used to define group characteristic traits and behaviours. Pair-wise comparisons were re-assessed for significance after multiple test correction for the 63 comparisons.

Traits were regarded as unique to a work-type if the work-type obtained a trait score distribution that was statistically significantly different, at the 0.05 level, from the trait score distributions of the other two work types.

Venous blood samples were obtained from 22 dogs and the samples transferred to Whatman FTA (Flinders Technology Associates) cards for submission to the genotyping supplier. A further 42 dogs were sampled using Performagene saliva collection kits (DNA Genotek, Ontario Canada) and DNA was extracted following standard kit-issued protocol. Samples were collected with University of Sydney animal ethics committee's approval (N00/10-2012/3/5837 and N00/10-2012/3/5928). Genotyping was conducted on the Illumina Canine High Density Genotyping array (172,939 markers) by Neogen/ Geneseek Nebraska USA.

The genetic similarity between working-type groups was assessed through the application of clustering and multi-dimensional scaling of genotyping data for 19 dogs classified as Paddock dogs, 11 dogs classified as Yard dogs and 34 dogs classified as Utility dogs in the package "Plink" [8].

\section{Results}

Trait means and standard errors are shown in Additional file 1: Table S2.

Compared with both Yard and Utility dogs, Paddock dogs had significantly lower trait scores for force (pressure applied by the dog in order to move livestock), willingness to back the stock and bite (frequency - assessed on a scale from never (score 1) to very frequently (score 5)).

Participants rated the quality of their ability in the manoeuvres and traits of cast, gather, force, cover, head, hold, balance, break, back, initiative, anticipation, trainability and natural-ability (extremely poor (score 1) excellent (score 5)). Working groups were rated with a mean force scores of $3.64 \pm 1.1,3.99 \pm 0.73$ and $4.15 \pm 0.89$ for Paddock, Utility and Yard groups, respectively (Additional file 1: Table S2). Paddock group scores for force were significantly lower than those of the other two working groups. Fifty-eight percent of Paddock dogs still scored either "very good" or "excellent" (compared with $70 \%$ for Utility and $80 \%$ for Yard dogs). With respect to the dog's willingness to back the stock: only $23 \%$ of Paddock dogs scored as either "very good" or "excellent" compared with $50 \%$ of Utility dogs and $71 \%$ of Yard dogs. It should be recognised that "excellent" force is not necessarily maximum force and is more likely to be highly appropriate force.

Compared with both Paddock and Utility dogs, the Yard dogs had significantly higher scores for hyperactivity and excitability (both with and without stock) and impulsiveness without stock (Table 1). They are also reported to take more time between stimulation (commands) and response (longer latency to respond). Their defining feature was a significantly higher mean score to back the stock. Unsurprisingly, as bite is a frequent requirement of the Yard work-type, Yard dogs were reported to bite/nip stock more frequently. The Yard dogs had significantly lower scores for calmness (with and without stock), less patience with stock, less ability to cast, gather, head or hold the stock than other working types. They also showed less eye (i.e., standing with their head lowered in a predatory stance, staring intently at the stock) and less balance when working stock (the ability of the dog to judge the optimal working distance from the livestock). They also attracted lower scores for break quality (the movement a dog performs to move around and redirect livestock, usually when some animals separate from the main group).

Utility dogs had scores that were intermediate between the Yard and Paddock dogs for bite and back. Indeed, all three groups differed significantly for these two traits. In general, the behaviour scores of the Utility work-type clustered more closely with the Paddock work-type than the Yard work-type. Of the 63 traits and manoeuvres measured, only six differed significantly between Paddock and 
Table 1 Pairwise comparison of work-type in the Australian Working Kelpie over 63 traits

\begin{tabular}{|c|c|c|c|c|}
\hline Comparison & Trait & $\begin{array}{l}\text { Welch's t-test } \\
\text { (unequal size\& unequal variance) }^{a}\end{array}$ & $\begin{array}{l}\text { Degrees of freedom } \\
\text { (Welch-Satterthwaite) }\end{array}$ & Probability \\
\hline \multirow[t]{43}{*}{ Paddock versus Yard } & confidence_stock & -0.641 & 59 & 0.3226 \\
\hline & calmness_stock & 3.033 & 61 & $0.0051^{b}$ \\
\hline & intelligence_stock & 1.133 & 54 & 0.2080 \\
\hline & trainability_stock & 0.915 & 58 & 0.2603 \\
\hline & boldness_stock & -0.923 & 55 & 0.2582 \\
\hline & patience_stock & 2.864 & 73 & 0.0078 \\
\hline & timidness_stock & 1.453 & 58 & 0.1383 \\
\hline & persistence_stock & 0.346 & 55 & 0.3737 \\
\hline & hyperactivity_stock & -3.485 & 53 & 0.0015 \\
\hline & initiative_stock & 0.565 & 60 & 0.3378 \\
\hline & excitability_stock & -4.267 & 58 & $0.0001^{*}$ \\
\hline & obedience_stock & -0.096 & 48 & 0.3950 \\
\hline & nervousness_stock & -0.054 & 56 & 0.3965 \\
\hline & impulsiveness_stock & -3.269 & 57 & 0.0027 \\
\hline & stamina & -0.536 & 63 & 0.3436 \\
\hline & confidence_without_stock & -1.839 & 59 & 0.0746 \\
\hline & calmness_without_stock & 2.082 & 49 & 0.0477 \\
\hline & intelligence_without_stock & 0.135 & 57 & 0.3935 \\
\hline & trainability_without_stock & 0.000 & 57 & 0.3972 \\
\hline & boldness_without_stock & -0.100 & 60 & 0.3952 \\
\hline & patience_without_stock & 1.156 & 56 & 0.2027 \\
\hline & timidness_without_stock & 0.607 & 57 & 0.3295 \\
\hline & persistence_without_stock & 0.794 & 58 & 0.2887 \\
\hline & hyperactivity_without_stock & -2.955 & 58 & 0.0063 \\
\hline & initiative_without_stock & -1.154 & 68 & 0.2037 \\
\hline & excitability_without_stock & -2.401 & 56 & 0.0244 \\
\hline & obedience_without_stock & 0.321 & 50 & 0.3766 \\
\hline & nervousness_without_stock & -0.397 & 62 & 0.3668 \\
\hline & impulsiveness_without_stock & -3.407 & 58 & 0.0018 \\
\hline & sociability & -0.047 & 54 & 0.3967 \\
\hline & friendliness & 1.133 & 55 & 0.2081 \\
\hline & cast & 2.896 & 51 & 0.0076 \\
\hline & gather & 3.788 & 51 & $0.0006^{*}$ \\
\hline & force & -2.692 & 59 & 0.0123 \\
\hline & cover & 2.177 & 51 & 0.0394 \\
\hline & head & 2.322 & 52 & 0.0291 \\
\hline & hold & 1.842 & 50 & 0.0744 \\
\hline & balance & 2.499 & 57 & 0.0195 \\
\hline & break & 0.657 & 57 & 0.3191 \\
\hline & back & -5.864 & 61 & $0.0000^{*}$ \\
\hline & initiative & -1.333 & 57 & 0.1631 \\
\hline & anticipation & -0.369 & 51 & 0.3704 \\
\hline & trainability & -0.731 & 56 & 0.3028 \\
\hline
\end{tabular}


Table 1 Pairwise comparison of work-type in the Australian Working Kelpie over 63 traits (Continued)

\begin{tabular}{|c|c|c|c|c|}
\hline Comparison & Trait & $\begin{array}{l}\text { Welch's t-test } \\
\text { (unequal size\& unequal variance) }^{a}\end{array}$ & $\begin{array}{l}\text { Degrees of freedom } \\
\text { (Welch-Satterthwaite) }\end{array}$ & Probability \\
\hline & natural_ability & 1.843 & 51 & 0.0742 \\
\hline & eye & 1.178 & 49 & 0.1974 \\
\hline & confidence_level & -0.149 & 49 & 0.3924 \\
\hline & calmness_level & 2.305 & 57 & 0.0300 \\
\hline & boldness & -1.624 & 47 & 0.1071 \\
\hline & bark & -1.755 & 63 & 0.0862 \\
\hline & bite & -1.462 & 59 & 0.1367 \\
\hline & cast & 0.701 & 42 & 0.3089 \\
\hline & force & -3.540 & 51 & 0.0013 \\
\hline & bite_frequency & -5.615 & 65 & $0.0000^{*}$ \\
\hline & bark_frequency & -1.597 & 51 & 0.1116 \\
\hline & overall_ability & 0.000 & 59 & 0.3973 \\
\hline & obedience_come & 1.075 & 54 & 0.2217 \\
\hline & obedience_sit & 0.239 & 49 & 0.3855 \\
\hline & obedience_stay & 1.922 & 56 & 0.0643 \\
\hline & listening & -0.092 & 53 & 0.3953 \\
\hline & latency & -3.091 & 46 & 0.0047 \\
\hline & tricks & -1.211 & 43 & 0.1896 \\
\hline & distraction & -1.554 & 44 & 0.1191 \\
\hline & fetch & 0.273 & 31 & 0.3807 \\
\hline \multicolumn{5}{|c|}{ Paddock versus Utility } \\
\hline & confidence_stock & -1.921 & 198 & 0.0635 \\
\hline & calmness_stock & 0.152 & 235 & 0.3939 \\
\hline & intelligence_stock & 0.575 & 233 & 0.3377 \\
\hline & trainability_stock & -0.086 & 233 & 0.3970 \\
\hline & boldness_stock & -1.367 & 215 & 0.1564 \\
\hline & patience_stock & 0.235 & 228 & 0.3876 \\
\hline & timidness_stock & 0.489 & 243 & 0.3535 \\
\hline & persistence_stock & 0.486 & 222 & 0.3539 \\
\hline & hyperactivity_stock & 0.000 & 227 & 0.3985 \\
\hline & initiative_stock & -0.585 & 231 & 0.3356 \\
\hline & excitability_stock & -0.416 & 226 & 0.3654 \\
\hline & obedience_stock & -0.432 & 239 & 0.3630 \\
\hline & nervousness_stock & 0.165 & 240 & 0.3931 \\
\hline & impulsiveness_stock & -1.337 & 251 & 0.1630 \\
\hline & stamina & -0.349 & 221 & 0.3749 \\
\hline & confidence_without_stock & -1.694 & 225 & 0.0951 \\
\hline & calmness_without_stock & -0.647 & 233 & 0.3230 \\
\hline & intelligence_without_stock & 1.381 & 245 & 0.1535 \\
\hline & trainability_without_stock & -0.675 & 235 & 0.3170 \\
\hline & boldness_without_stock & -1.943 & 217 & 0.0608 \\
\hline & patience_without_stock & 0.247 & 231 & 0.3865 \\
\hline & timidness_without_stock & 0.950 & 226 & 0.2534 \\
\hline
\end{tabular}


Table 1 Pairwise comparison of work-type in the Australian Working Kelpie over 63 traits (Continued)

\begin{tabular}{|c|c|c|c|c|}
\hline Comparison & Trait & $\begin{array}{l}\text { Welch's t-test } \\
\text { (unequal size\& unequal variance) }^{\mathrm{a}}\end{array}$ & $\begin{array}{l}\text { Degrees of freedom } \\
\text { (Welch-Satterthwaite) }\end{array}$ & Probability \\
\hline & persistence_without_stock & 0.168 & 219 & 0.3929 \\
\hline & hyperactivity_without_stock & 0.000 & 223 & 0.3985 \\
\hline & initiative_without_stock & -1.715 & 235 & 0.0919 \\
\hline & excitability_without_stock & -1.706 & 221 & 0.0933 \\
\hline & obedience_without_stock & -0.412 & 224 & 0.3660 \\
\hline & nervousness_without_stock & 1.033 & 222 & 0.2336 \\
\hline & impulsiveness_without_stock & -1.134 & 234 & 0.2093 \\
\hline & sociability & -0.307 & 225 & 0.3800 \\
\hline & friendliness & -0.350 & 206 & 0.3747 \\
\hline & cast & -1.336 & 223 & 0.1633 \\
\hline & gather & -0.089 & 225 & 0.3969 \\
\hline & force & -2.879 & 216 & 0.0067 \\
\hline & cover & -0.597 & 225 & 0.3332 \\
\hline & head & -0.623 & 231 & 0.3279 \\
\hline & hold & -1.910 & 228 & 0.0648 \\
\hline & balance & -1.104 & 228 & 0.2164 \\
\hline & break & -2.218 & 230 & 0.0346 \\
\hline & back & -4.696 & 231 & $0.0000^{*}$ \\
\hline & initiative & -1.121 & 230 & 0.2124 \\
\hline & anticipation & -1.613 & 233 & 0.1087 \\
\hline & trainability & -0.808 & 226 & 0.2872 \\
\hline & natural_ability & -0.824 & 209 & 0.2834 \\
\hline & eye & 0.325 & 250 & 0.3780 \\
\hline & confidence_level & -0.538 & 229 & 0.3446 \\
\hline & calmness_level & -0.503 & 220 & 0.3509 \\
\hline & boldness & -2.377 & 218 & 0.0242 \\
\hline & bark & -0.076 & 231 & 0.3973 \\
\hline & bite & -1.761 & 250 & 0.0848 \\
\hline & cast & -0.888 & 245 & 0.2685 \\
\hline & force & -1.392 & 222 & 0.1511 \\
\hline & bite_frequency & -2.379 & 235 & 0.0240 \\
\hline & bark_frequency & -2.070 & 240 & 0.0473 \\
\hline & overall_ability & -1.767 & 213 & 0.0839 \\
\hline & obedience_come & -0.480 & 237 & 0.3551 \\
\hline & obedience_sit & 0.492 & 244 & 0.3530 \\
\hline & obedience_stay & 0.315 & 240 & 0.3792 \\
\hline & listening & 0.072 & 241 & 0.3975 \\
\hline & latency & -1.307 & 212 & 0.1695 \\
\hline & tricks & -0.080 & 210 & 0.3972 \\
\hline & distraction & -0.133 & 191 & 0.3949 \\
\hline & fetch & 0.836 & 139 & 0.2803 \\
\hline \multicolumn{5}{|c|}{ Yard versus Utility } \\
\hline & confidence_stock & -0.582 & 43 & 0.3338 \\
\hline
\end{tabular}


Table 1 Pairwise comparison of work-type in the Australian Working Kelpie over 63 traits (Continued)

\begin{tabular}{|c|c|c|c|c|}
\hline Comparison & Trait & $\begin{array}{l}\text { Welch's t-test } \\
\text { (unequal size\& unequal variance) }^{a}\end{array}$ & $\begin{array}{l}\text { Degrees of freedom } \\
\text { (Welch-Satterthwaite) }\end{array}$ & Probability \\
\hline & calmness_stock & -3.058 & 52 & 0.0050 \\
\hline & intelligence_stock & -0.806 & 47 & 0.2854 \\
\hline & trainability_stock & -1.016 & 50 & 0.2358 \\
\hline & boldness_stock & 0.103 & 44 & 0.3945 \\
\hline & patience_stock & -2.877 & 58 & 0.0078 \\
\hline & timidness_stock & -1.144 & 54 & 0.2054 \\
\hline & persistence_stock & -0.052 & 45 & 0.3962 \\
\hline & hyperactivity_stock & 3.641 & 46 & 0.0010 \\
\hline & initiative_stock & -1.010 & 51 & 0.2373 \\
\hline & excitability_stock & 4.215 & 48 & $0.0002^{*}$ \\
\hline & obedience_stock & -0.148 & 44 & 0.3923 \\
\hline & nervousness_stock & 0.167 & 51 & 0.3913 \\
\hline & impulsiveness_stock & 2.310 & 58 & 0.0296 \\
\hline & stamina & 0.319 & 50 & 0.3769 \\
\hline & confidence_without_stock & 0.766 & 49 & 0.2946 \\
\hline & calmness_without_stock & -2.520 & 44 & 0.0192 \\
\hline & intelligence_without_stock & 0.828 & 54 & 0.2807 \\
\hline & trainability_without_stock & -0.462 & 50 & 0.3561 \\
\hline & boldness_without_stock & -1.233 & 47 & 0.1848 \\
\hline & patience_without_stock & -1.043 & 48 & 0.2291 \\
\hline & timidness_without_stock & 0.000 & 48 & 0.3968 \\
\hline & persistence_without_stock & -0.731 & 46 & 0.3024 \\
\hline & hyperactivity_without_stock & 3.130 & 48 & 0.0042 \\
\hline & initiative_without_stock & -0.128 & 58 & 0.3939 \\
\hline & excitability_without_stock & 1.415 & 46 & 0.1458 \\
\hline & obedience_without_stock & -0.573 & 43 & 0.3354 \\
\hline & nervousness_without_stock & 1.166 & 50 & 0.2003 \\
\hline & impulsiveness_without_stock & 2.770 & 50 & 0.0104 \\
\hline & sociability & -0.146 & 46 & 0.3924 \\
\hline & friendliness & -1.435 & 43 & 0.1417 \\
\hline & cast & -3.819 & 43 & $0.0006^{*}$ \\
\hline & gather & -4.002 & 44 & $0.0004^{*}$ \\
\hline & force & 0.904 & 47 & 0.2624 \\
\hline & cover & -2.621 & 44 & 0.0152 \\
\hline & head & -2.791 & 45 & 0.0101 \\
\hline & hold & -3.015 & 43 & 0.0058 \\
\hline & balance & -3.363 & 48 & 0.0022 \\
\hline & break & -2.177 & 48 & 0.0395 \\
\hline & back & 2.780 & 52 & 0.0101 \\
\hline & initiative & 0.634 & 49 & 0.3235 \\
\hline & anticipation & -0.600 & 45 & 0.3302 \\
\hline & trainability & 0.236 & 47 & 0.3856 \\
\hline & natural_ability & -2.422 & 41 & 0.0239 \\
\hline
\end{tabular}


Table 1 Pairwise comparison of work-type in the Australian Working Kelpie over 63 traits (Continued)

\begin{tabular}{|c|c|c|c|c|}
\hline Comparison & Trait & 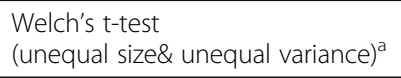 & $\begin{array}{l}\text { Degrees of freedom } \\
\text { (Welch-Satterthwaite) }\end{array}$ & Probability \\
\hline & eye & -0.986 & 49 & 0.2428 \\
\hline & confidence_level & -0.154 & 43 & 0.3918 \\
\hline & calmness_level & -2.776 & 46 & 0.0104 \\
\hline & boldness & 0.434 & 40 & 0.3600 \\
\hline & bark & 1.791 & 53 & 0.0812 \\
\hline & bite & 0.176 & 59 & 0.3911 \\
\hline & cast & -1.131 & 41 & 0.2081 \\
\hline & force & 2.881 & 43 & 0.0082 \\
\hline & bite_frequency & 4.084 & 55 & $0.0002^{*}$ \\
\hline & bark_frequency & 0.372 & 47 & 0.3697 \\
\hline & overall_ability & -1.209 & 46 & 0.1902 \\
\hline & obedience_come & -1.418 & 48 & 0.1452 \\
\hline & obedience_sit & 0.048 & 46 & 0.3963 \\
\hline & obedience_stay & -1.759 & 51 & 0.0858 \\
\hline & listening & 0.140 & 51 & 0.3930 \\
\hline & latency & 2.434 & 41 & 0.0233 \\
\hline & tricks & 1.199 & 40 & 0.1921 \\
\hline & distraction & 1.519 & 40 & 0.1255 \\
\hline & fetch & 0.235 & 26 & 0.3838 \\
\hline
\end{tabular}

${ }^{*}$ Comparisons remaining significant after multiple-test correction for 63 tests $(p<0.000794)$

${ }^{a}$ Negative scores indicate a lower trait mean score for the first listed group (e.g. Paddock in Paddock versus Yard)

${ }^{b}$ Probabilities $<0.05$ are highlighted

Utility dogs (force, break, back, boldness, bite-frequency and bark-frequency). Between Yard and Utility dogs, 21 characteristics differed significantly. Between Yard and Paddock dogs, 20 characteristics differed (18 of which were the same as those differing between the Yard and Utility dogs).

Overall-ability, natural-ability and trainability did not differ significantly among working-type groups. Overallability (scored between "worst dog I have ever seen/ trained" to "best dog I have ever seen/trained) is perceived by breeders and handlers to represent a culmination of breeding, training and handling". Natural-ability is regarded as the dog's inherent talent for the working tasks and is thought to more likely represent genetic potential. Trainability is the ease with which the dog can be trained to accomplish the skills required for its working context.

The proportions of dogs at each scoring level for the traits of Overall-ability and Natural-ability across working types are shown in Fig. 1a and b respectively.

Paddock dogs, Yard dogs and Utility dogs were unable to be genetically differentiated on a whole-genome level (that is, the genomic inflation estimate of lambda (based on median chi-squared statistic $=1$ ). Similarly, clustering analysis identified dogs in the analysis as a single genetic cluster although there is some evidence of potential cross-breeding within the study population as is evidenced by the directional trends in the data for the Paddock and Utility dogs (Fig. 2). Genetically, Yard dogs were centrally located in the Australian Working Kelpie population cluster based on genetic variation.

\section{Discussion}

This study of herding dog owners' reports of their dogs' behavioural attributes clearly demonstrates that, over the three work-types of dogs assessed, owners and handlers held their dogs in high regard. For example, the majority of participant dogs (86\%) were assessed as having overall-ability that was "above average" or "the best dog I have ever owned/trained" and had "good" or "excellent" natural-ability. Conversely, very few dogs rated poorly for their overall-ability; with only $6 \%$ being judged as "below average" or "one of the worst dogs I have ever owned/trained". Even fewer $(\sim 4 \%)$ were judged to have "extremely poor" or "poor" natural-ability. Of course, this may reflect respondent bias in that owners of dogs that are currently disappointing may be disinclined to spend time describing them for research purposes or it is possible that dogs already assessed as poor are no longer with them. Compared with the owners of Paddock and Utility dogs, the owners of Yard dogs were more likely to be critical of their dogs; with $11 \%$ being rated as "below average" or "one of the worst dogs I have ever 

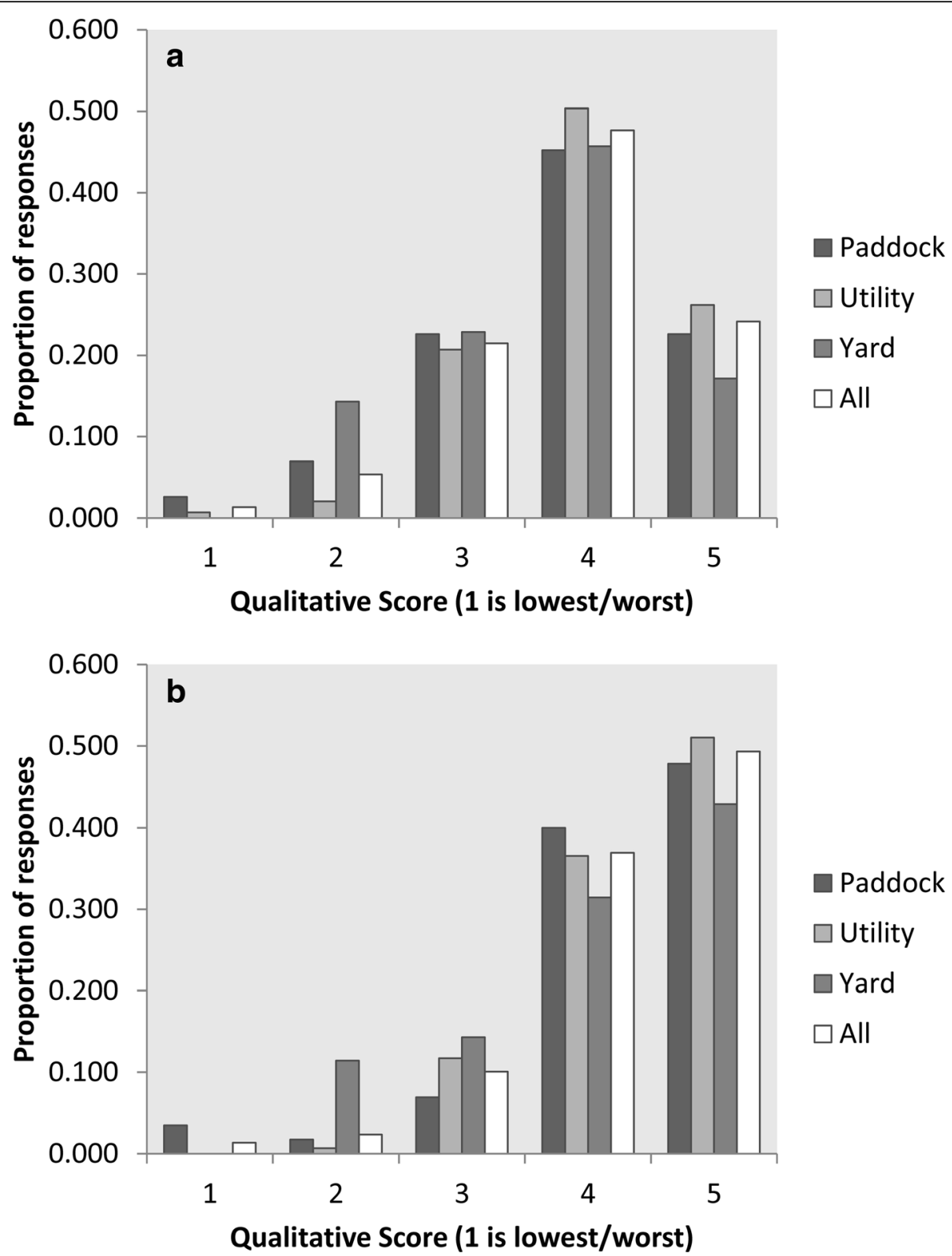

Fig. 1 Proportion of dogs at each qualitative trait score ( 1 = worst, 5 = best) for a overall-ability and $\mathbf{b}$ natural-ability by work-type in the Australian Working Kelpie

owned/trained" and only $74 \%$ rated at "above average" or "one of the best dogs I have ever owned/trained" (Fig. 1). The relatively small number of Yard dogs assessed means that it is possible that these ratings reflect a form of sampling error.

Two traits (bite and back) differed significantly across all three groups and these, along with force, uniquely differentiated the Paddock dogs (which had the lowest scores for all three attributes). Yard dogs had significant strengths in several attributes pertaining to energy level, vocalisation and intensity of interaction with stock (calmness, hyperactivity, excitability, bark, bite, back, and patience). In contrast, they also had significantly lower scores for the trained manoeuvres of particular value in the context of paddock. It is possible that this finding is a function of training and exposure, rather than innate talent. Across all of the assessed attributes, Yard dogs were the most differentiated group but only 35 of 298 dogs were used for this purpose. The higher level of bark and bite demonstrated by the yard dogs is a characteristic of the desirability of these traits in the work context.

This work underlies a broader project goal to create a breeding program aiming to reduce loss of dogs from 


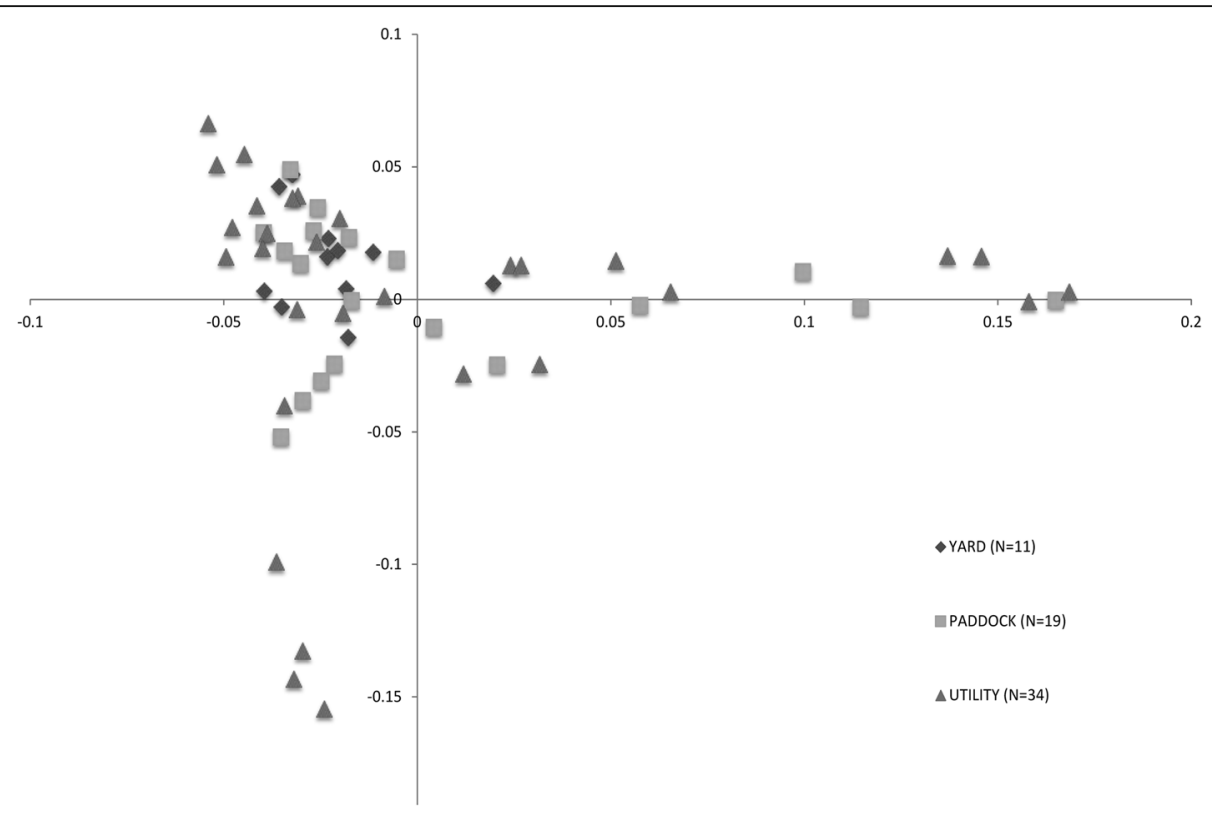

Fig. 2 Multi-dimensional scaling plot displaying genetic distances between individuals from Australian Working Kelpie populations described as Paddock, Yard and Utility working types demonstrating that there is no clear genetic differentiation between the working types (Table S3). (Legend: Paddock ( $N=19)$-square marker; Yard ( $N=11)$ - diamond marker; Utility ( $N=34)$ - triangular marker)

the industry through their being unsuited to the purpose for which they were bought. Our work demonstrates that separate breeding objectives for the groups are not required. The three work-types of dogs partitioned in this analysis did not differ significantly in overall-ability, natural-ability or trainability, suggesting that breeding for "all-rounders" does not endanger the global working quality of this breed when dogs are used in their correct context. This indicative finding was also supported by the DNA analysis that showed that the work-types did not cluster separately at the genetic level. Despite this, people employing different working types have very different perceptions of what attributes are acceptable and desirable. For any breeding program that aims to influence the prevalence of a range of attributes, there will always be a distribution of quality for individual characters produced in any kennel.

Given the relatively limited demand for Yard dogs, it is expected that most breeders would rather specialise in either Paddock dogs or Utility dogs and then on occasion be able to effectively identify the outlier pups (from Utility and Paddock lines) with especially strong Yard attributes.

Mapping genes for bite and back which are the attributes that critically qualify the dogs for purpose might be central to the early identification of working homes for dogs, particularly for animals bred in Utility kennels. Alternatively, identifying other early predictors of these traits via behavioural testing would enhance welfare outcomes.

\section{Conclusions}

Specialist characteristics were displayed by dogs in the Yard Kelpie and Paddock Kelpie groups. In particular, Yard Kelpies demonstrate higher excitability, willingness to back the stock, and a higher tendency to bark and bite the stock. Conversely, Paddock Kelpies rarely display these characteristics. Utility Kelpies, as the name suggests, are intermediate between the other two groups and display the characteristics of both. Genetic analysis suggests that the Yard, Utility and Paddock Kelpies are not distinguishable at a DNA level. In conclusion, at this time there is no suggestion of a breed split in the Australian Working Kelpie generated by selection for work type. A common breeding objective should enable dogs to be produced that fulfil all potential working requirements. This reinforces the importance of breeder skill in recognising the phenotypic potential of pups in order to place them in appropriate working contexts.

\section{Additional file}

Additional file 1: Supplementary methods and tables. (DOCX $44 \mathrm{~kb}$ )

Acknowledgements

This work was funded by grants from the Rural Industries Research and Development Corporation, and the Working Kelpie Council of Australia. We gratefully acknowledge all of the dog owners that participated in the research.

Availability of data and materials

All data relevant to study are included in the manuscript and associated supplementary materials. 


\section{Authors' contributions}

CMW and PDM conceived and designed the project. JBE, EAA, LJM, DVR and CMW collected and analysed the data. All authors collaborated in the writing or the manuscript. All authors read and approved the final manuscript.

\section{Ethics approval and consent to participate}

Samples were collected with University of Sydney animal ethics committee's approval numbers (N00/10-2012/3/5837 and N00/10-2012/3/5928). Human participation consent was collected with University of Sydney Human Ethics Committee approval number (2012/658).

\section{Competing interests}

The authors declare that they have no competing interests.

\section{Glossary}

Backing

action of a dog jumping up onto sheep's backs in order to assist in moving them in tight spaces such as in yards, sheds or trucks.

Balance

position a dog assumes in relation to the livestock and the handler that Break

is best suited to move the livestock to the desired location efficiently.

Type of movement a dog performs to move around and redirect

livestock usually when some animals separate from the main group. Cast

initial movement of a dog around to the far side, in relation to the handler, of the livestock in order to gather and deliver them back towards the handler.

Cover

type of movement a dog uses around livestock while keeping them together.

Eye

postural behaviour that involves staring at livestock from a stationary position or involve stalking-like movement. Considered to be a remnant of stalking behaviour that forms part of the predatory sequence in wild dogs and wolves

Force

pressure applied by the dog in order to move livestock. Heading

movement of a dog to the front of a group of livestock to stop or Hold redirect their movement.

the action of a dog to keep livestock together.

From: McGreevy et al. [6]. Barton (ACT), Australia: Rural Industries Research and Development Corporation.

\section{Publisher's Note}

Springer Nature remains neutral with regard to jurisdictional claims in published maps and institutional affiliations.

Received: 26 March 2018 Accepted: 30 May 2018

Published online: 13 August 2018

\section{References}

1. Arnott ER, Peek L, Early JB, Pan AY, Haase B, Chew T, McGreevy PD, Wade CM. Strong selection for behavioural resilience in australian stock working dogs identified by selective sweep analysis. Canine Genet Epidemiol. 2015;2:6

2. The_Working_Kelpie_Council_of_Australia. Origin of the kelpie. 2017 [cited 2017 19/05/2017]; http://www.wkc.org.au/About-Kelpies/Origin-ofthe-Kelpie.php]. Available from: http://www.wkc.org.au/About-Kelpies/ Origin-of-the-Kelpie.php.

3. Early JB, Arnott ER, Wade CM, McGreevy PD. Manual muster: a critical analysis of the use of common terms in australian working dog manuals. Vet Behav. 2014;9(6):370-4

4. Arnott ER, Early JB, Wade CM, McGreevy PD. Environmental factors associated with success rates of australian stock herding dogs. PLoS One. 2014;9(8):e104457.

5. Arnott ER, Early JB, Wade CM, McGreevy PD. Estimating the economic value of australian stock herding dogs. Anim Welf. 2014;23(2):189-97.
6. McGreevy, P.D., Wade, C.M., Arnott, E.R. and Early, J.B. Valuable behavioural phenotypes in australian farm dogs. 2015 [cited 2017; Available from: https://doggenetics.net.au/Kelpie/LivestockHerdingForm.pdf.

7. Welch BL. The generalization of "student's" problem when several different population variances are involved. Biometrika. 1947;34(1-2):28-35.

8. Purcell S, Neale B, Todd-Brown K, Thomas L, Ferreira MA, Bender D, Maller J, Sklar P, de Bakker PI, Daly MJ, Sham PC. Plink: a tool set for whole-genome association and population-based linkage analyses. Am J Hum Genet. 2007; 81(3):559-75.

\section{Ready to submit your research? Choose BMC and benefit from:}

- fast, convenient online submission

- thorough peer review by experienced researchers in your field

- rapid publication on acceptance

- support for research data, including large and complex data types

- gold Open Access which fosters wider collaboration and increased citations

- maximum visibility for your research: over $100 \mathrm{M}$ website views per year

At $\mathrm{BMC}$, research is always in progress.

Learn more biomedcentral.com/submissions 